\title{
The revolution strategy of online courses in new technology environment
}

\author{
Donghui Jia, Jin Liang \\ School of Information Technology in Education, South China Normal University, Guangzhou, China \\ jiadonghui@m.scnu.edu.cn, liang-1-1@163.com
}

Keywords: online courses; Mooc;open; individuation.

\begin{abstract}
The forms of online courses have changed a lot with the rapid development of information technology, the old forms of online courses can't adapt to the changes of online learning. This article is aimed at the need and characteristics of the development of online courses in new environment of technology and discusses the strategy of online courses revolution to find solutions to the development of online courses.
\end{abstract}

\section{Introduction}

The rapid development of new technologies have changed many areas in the world, some industries have been totally different than before. Some people begin to doubt that the changes in education are not as outstanding as in other fields. There are quite many online courses nowadays, but the quality of them are not as attractive as we expect[1]. Learners may feel that online courses can't provide excellent learning experience and learning effects. This situation is quite in need to change if online courses producers want to have a good performance in the new environment.

Meanwhile, the new online courses forms which named Moocs are developing very fast in worldwide, it gives people the hope of future online courses. More and more researchers study how to develop future online courses with the new characteristics of online courses. Reforms are necessary to take and new ways of thinking are in need. Courses designers have to make it clear what are learners really hope to get. Only when they make appropriate changes to online courses can they really attract learners.

\section{Characteristics of online courses in new technology environments}

\section{Online learning websites appear quickly}

The online learning is very popular and the market demand is huge in China, more and more people need to learn online, lifelong learning is a trend in new century. A large amount of online learning companies come out, and these companies have their own characteristics and special customers. They explore the new types and goals of future online courses. Udemy is a company working on higher and profession education, who earns by providing service to users. Anyone can build or learn courses on their website, this company builds an education C2C platform[2]. Knowre is aimed at math education in primary and middle school degree. Its instruction design is working by tasks, this makes math as interesting as game[3]. Codeacademy is a platform to teach how to code online, its instruction task is designed as interesting as games, even new learners can find the feel of a programmer[4],the achievement feeling can turn into a lasting learning motivation.

\section{The enthusiasm of building online courses is quite high in universities.}

Moocs are developing in a incredible speed in the global. Top universities in America try every effort to popularize their excellent online courses. Learners from all the world can enjoy their excellent education quality and campus culture. The influence of these universities is getting much bigger than before. Face to this drastic competition, more and more universities are planning to make their own online courses with their own characteristics. They hope to catch up with this trend, the situation is quite different from that universities are not very active to make online courses. 
Universities in China are also thinking about to make online courses, this is different from that they make online courses to complete tasks by government in before. These universities try to improve their international influence. Education in the global time is much more open than before. Only to complete in open mind can universities keep their influence.

\section{The cooperation between universities and companies in making online courses is more frequent.}

With the rapid development of Moocs, more universities design and make their online courses and more companies notice this big chance. Some universities give the tasks of making online courses to professional companies, these companies have more advantages in these fields. Universities only need to design courses and teachers have classes, the other parts are running by companies. The speed of making courses, upload courses and popularize courses are more fast. The cost of making a courses is cheaper because they both use their advantages. Universities are putting more attention to improve course quality, companies are driven by profit and working hard. The ecosystem between users, universities and companies are building fast. It's a trend to build ecosystem in all industries.

\section{The price to get knowledge is cheaper than before,the distance between mass and experts is closer than before. \\ More and more top universities open their courses to mass in the world, the gate to get knowledge is easier to open than before. The speed to spread knowledge is much faster than before, the mass have more choices to listen excellent lessons. Education is more fair than before, the mode that higher education is for excellent people is being broken out[5]. Knowledge is shinning more corners of the world, everyone has the right to accept education if his place has net access.}

\section{Online courses are more personalized}

Traditional online courses are made in the style that teachers teach in a serious way, almost all courses are alike[6].This is not fit for today's learners, they want more personalized courses which fit their learning style. Teachers who make online courses nowadays need to think about the need of online learners. They need to make their courses more interesting and attractive, only interesting courses can attract more learners' eyes. Online courses makers should think of their location for courses, it's important for them to have their own styles. They also need to provide personalized services for learners, if they can do it well enough, it will become their big advantages.

\section{The quality of online courses need be excellent}

It's a trend that more universities make online coursers with professional companies, so the requirement for online courses is higher than before. These companies usually shoot and edit courses for universities, they have their teams and ideas, market is familiar for them. Learners have better online learning experience than before, it's guarantee for the positivity of learners. Learners nowadays have more choices than before, they know what they want on net[7].If a course is made in poor quality, he will not stay one more second. This is quite different from school courses.

\section{The idea of online courses is more creationary}

There are quite a lot of online courses, how to make learners remember a course quickly and insist to complete it is a big challenge. It requires excellent teaching level, good instruction design and fresh ideas for the content. Amazing originality and publicity can attract learners' eyes fast. If a learner doesn't remember a course at first glance, he will not glance back to notice it. So how to make a course unique is quite a challenge for designers.

\section{Online courses are more open than before.}

Traditional online courses are made by universities, this limits the diversity and openness of them. Many people who have excellent ideas and rich experience can't make online courses, it limits the spread of knowledge. Online courses now give more the people the right to make and spread online courses. If you have good ideas and topics, you can open a online course for the mass. This encourages more people in more fields to show their talent on net, the spread of knowledge is more diversified. 


\section{The interaction experience of online courses is better than before.}

With the development of interaction technology and the increasing need for interaction. Online course makers have to think about how to enhance the interaction experience to let learners put forward views, discuss questions and ask questions. Online courses now have the function to leave message in discuss area, teachers and learners can communicate easier, it makes learning more deeply. Learners can easily share their learning result to their friends by social network medias. Learning is a more interactive thing.

\section{Mobile learning combines with online courses more close..}

People nowadays are not satisfied with only communication with mobile devices, learning by mobile devices has been a new learning form in the time. This requires online courses can not only be learnt by computers. Course developers should think about how to send online course content to learners. Mobile learning is full of life, it's necessary to enhance online learning experience. Mobile devices have very rich functions now, they can support online learning better. Many courses are trying to publish their mobile version.

\section{The revolution strategy of online courses in new technology environments}

The development of technology has brought great changes to the forms of online courses, the demand of online learners has become more multiple, personalized and intelligentized. It calls revolution to satisfy these changes, next is how to revolution in this new environment.

\section{Courses forms change to micro lectures.}

The pace of life is very fast nowadays, people's learning time is quite short. It's no longer possible for people to take a long time in a day to learn. Learners prefer to learn what they are interested in their rest time. It requires course designers to divide their courses into short parts. A course clip is better just about a knowledge point and the time is better in 10 minutes, 3 to 5 minutes is perfect. Learners are easy to feel tired and boring if a course clip is too long. Learners often learn on their ways to work, rest time at meal or leisure time after work, these all require the courses are easy to show important ideas. Nobody wants to waste his time on long but useless content. Every micro lecture should have main idea and well-designed instruction activity. It's not just cut videos into clips. All micro videos are better made in similar styles, it will make learners feel tidy. There are a lot of excellent micro lectures on the internet, they can be examples of how to make excellent ones. This is necessary for designers to master.

\section{Content of courses should be more neoteric .}

There are so many online courses now, it's really hard for learners to choose what they are interested in. So online courses should change their styles into more interesting and newer, it's better topics people are concerned about. Only by making courses fresh enough while guarantee the quality of courses can keep the interest of learners. Most of online learners are teenagers, they like fresh things and hope to learn what is happening new in the world. It's not enough to just move what is in books into online courses. It needs more creative work. Teachers can combine popular topics with their courses, it will be quite interesting for students.

\section{Courses' teaching style needed be more multiple .}

People's learning style is becoming more multiple in the internet age, traditional teaching style can no longer satisfy people's demand. Teenagers are more fond of learning online, how to understand their needs is important for online course designers. Teachers have to adapt to the changing time, keep their status young enough. They also need to keep their language style fun and active, it's better they have their own characteristics. These successful online courses all have their special styles.It won't get good effect if the course style is old and boring.

\section{Courses' interaction experience should be enhanced.}

When students are in real classes, they can not only listen to teachers, but also can communicate with teachers and ask their doubts to teachers. If courses are made online, it will be a challenge how 
to keep these interaction experience. With the development of new technologies, it's possible to provide more real interaction experience. In the past online courses, there are courses discussion district for students to ask questions. But it's often seen that the students not receive replies in time, it will lower the efficiency to learn. In future online courses, these interaction functions are likely to be enhanced.

\section{Courses' mobile version are needed to be developed.}

Considered of learners' mobile learning habit, online courses are needed to be designed both computer version and mobile version. Mobile learning is still in high speed development, there are many fields to explore. Internet companies are willing to try to provide mobile learning content, it's big chance for universities to cooperate with them. Mobile net speed is much faster than before, it's easier to watch videos and communicate with mobile devices. Mobile courses need think about how to make it cool to learn in mobile way. Most people in future will choose to learn what they want on mobile devices. It should be easy enough for learners to start a course on mobile devices and enjoy the process of learning it.

\section{Improving learning achievement's authentication is necessary.}

It's an embarrassing situation that learning achievement of online courses are not accepted by most people. People believe that the certification which is got in schools is efficient. When a graduate finds job, people only admit certification which is traditional. With the trend that more universities join Moocs, it's possible for learners to get scores in these schools. Driven by the trend, it's a dawn that online course will be admitted more in the future. Universities should cooperate more with other universities to improve communication. Education is becoming more fair than before because of internet. Universities should take responsibility to share excellent education to more ordinary people.

\section{Online courses are made more professional.}

It's a pity that many courses made by universities are wasted in the past because of poor making quality. It often costs much to make these courses, but the effect is so disappointed. Universities can give the making part to professional companies in future. Universities and companies just do well their parts, it will be the best use of resource. Learners are happy to see high quality courses, it will be an ideal result. It's a wise choice to give jobs to whom are best in this fields. It's a time that only best quality can survive, market doesn't accept which is not perfect. Universities should think more about market rules, once their courses are online, their users are all over from the world. They need to compete with top universities in the world.

\section{Courses' update and management needed be valued.}

It is a problem that many courses are just left there after they are online. Learners may meet many problems when they learn online, but they don't know how to solve and ask whom for help. These courses are lack of management, nobody takes responsibility for them. This situation should be improved in future. Universities can give the job to companies, they will check the problems and repair them. The cost will be much lower and efficiency will be higher. It's normal that there will be some mistakes in the courses, how to solve these mistakes in time is important because it's guarantee for the course's quality. Knowledge is increasing every day in this period, online courses should increase knowledge which is related to their courses online to keep the content in the course is always new.

\section{Courses need combine the characteristics of internet .}

No matter the courses are put on computers and mobiles, designers should know the characteristics of internet development. Many examples show that if a course is not designed as internet rules, it will not attract learners. Online learners' habit is important, when they will learn, how long time they learn every time and so on are needed to be thought about. When a course is online, its popularization also should obey the rules of internet. Designers should realize the power of internet, if a course is excellent enough, it will soon spread all the world, the users will be a 
unbelievable scale. The influence of an excellent course can improve an university's fame in the world.

\section{Conclusion}

The world is being changed fast by many new technologies, people's online learning habit are different from before. Online courses have to make changes to adapt to this new environment. It's a chance that online course can make big achievement if course designers can master the needs of learners. The prospect of online courses is very amazing, only by making suitable changes in this new environment can online courses develop in this trend. The nature of education is to spread knowledge and cultivate future talents. Traditional courses are limited in classrooms, their influence is very limited. New technologies break out the boundaries of knowledge. It's a best time to share and communicate excellent culture. There are so many topics which can be made into excellent online courses. If online courses designers think carefully how to use new technologies to develop their courses, it will make significant effects. Realize the power of new technologies deeply and use them properly, online courses will make great achievement.

\section{Acknowledgment}

This research was financially supported by the 2014 Guangzhou Scientific Plan Project, which number is $2014 \mathrm{~J} 4100079$.

\section{References}

[1] A. Anderson,D. Huttenlocher,J. Kleinberg, “Engaging with massive online courses,”Proceedings of the 23rd international conference on World wide web.ACM, 2014:687-698.

[2] Udemy.Homepage[EB/OL]. http://www.udemy.com

[3] Knowre.Homepage[EB/OL]. http://www.knowre.com

[4] Codeacademy.Homepage[EB/OL].http://www.codeacademy.com

[5] K.F. Hew,W.S. Cheung, "Students' and instructors' use of massive open online courses (MOOCs):Motivations and challenges,” Educational Research Review,2014,12:45-58.

[6] S.S. Jaggars, “Choosing between online and face-to-face courses: Community college student voices,”.American Journal of Distance Education, 2014, 28(1):27-38.

[7] A. Margaryan,M. Bianco and A. Littlejohn,“Instructional quality of Massive Open Online Courses (MOOCs),”Computers \& Education, 2015,80:77-83. 